Voss, H., Vogel, A., Wagemans, A.M.A., Francke, A.L., Metsemakers, J.F.M., Courtens, A.M., Veer, A.J.E. de. Advance care planning in the palliative phase of people with intellectual disabilities: analysis of medical files and interviews. Journal of Intellectual Disability Research: 2019, 63(10), p. 1262-1277

\begin{tabular}{|c|c|}
\hline Postprint version & \\
\hline Journal website & https://onlinelibrary.wiley.com/doi/abs/10.1111/jir.12664 \\
\hline Pubmed link & https://www.ncbi.nlm.nih.gov/pubmed/31237063 \\
\hline DOI & $10.1111 /$ jir.12664 \\
\hline
\end{tabular}

This is a Nivel certified Post Print, more info at nivel.nl

\title{
Advance care planning in the palliative phase of people with intellectual disabilities: analysis of medical files and interviews
}

\author{
H. Voss, ${ }^{1}$ A. Vogel, ${ }^{2}$ A. M. A. Wagemans, ${ }^{2,3,6}$ A. L. Francke, ${ }^{1,4,5}$ J. F. M. \\ Metsemakers, ${ }^{6}$ A. M. Courtens ${ }^{3}$ \& A. J. E. deVeer ${ }^{1}$
}

\footnotetext{
${ }^{1}$ Verpleging \& Verzorging, Netherlands Institute for Health Services Research (Nivel), Utrecht, The Netherlands

${ }^{2}$ Maasveld, Medische Dienst, Koraal, Maastricht, The Netherlands

${ }^{3}$ Expertise Centre for Palliative Care, Maastricht University Medical Centre, Maastricht, The Netherlands

${ }^{4}$ Amsterdam Public Health Research Institute (APH), VU Medical Center, Amsterdam, The Netherlands

${ }^{5}$ Expertise Center for Palliative Care Amsterdam, VU Medical Center, Amsterdam, The Netherlands

${ }^{6}$ Department of Family Medicine, Faculty of Health, Medicine and Life Science, Maastricht University, Maastricht, The Netherlands
}

\begin{abstract}
Background: Advance care planning (ACP) is a process in which professionals, patients and their relatives discuss wishes and options for future care. ACP in the palliative phase reduces the chance that decisions have to be taken suddenly and can therefore improve the quality of life and death. The primary aim of this study is to explore how ACP takes place in cases of people with intellectual disabilities (ID).

Method: Medical files were analysed, and interviews were held in six care organisations for people with mild to severe ID. The data concerned people with ID $(n=30), 15$ in the palliative phase, identified using the 'surprise question', and 15 who had died after an identifiable period of illness. Additional pre-structured telephone interviews were conducted with their relatives $(n=30)$ and professionals $(n=33)$.

Results: For half of the people with ID who had died, the first report in their file about palliative care (needs) was less than 1 month before their death. Professionals stated that ACP was started in response to the person's deteriorating health situation. A do-not-
\end{abstract}


Voss, H., Vogel, A., Wagemans, A.M.A., Francke, A.L., Metsemakers, J.F.M., Courtens, A.M., Veer, A.J.E. de. Advance care planning in the palliative phase of people with intellectual disabilities: analysis of medical files and interviews. Journal of Intellectual Disability Research: 2019, 63(10), p. 1262-1277

attempt-resuscitation order was recorded for nearly all people with ID (93\%). A smaller group also had other agreements between professionals and relatives documented in their files, mainly about potentially life-sustaining treatments (43\%) and/or hospitalisation admissions (47\%). Relatives and professionals are satisfied with the mutual cooperation in ACP in the palliative phase. Cognitive and communication disabilities were most frequently mentioned by relatives and professionals as reasons for not involving people with ID in ACP.

Conclusions: Advance care planning in the palliative phase of people with ID focuses mainly on medical issues at the end of life. Specific challenges concern a proactive identification of changing needs, fear to initiate ACP discussions, documentation of ACP in medical files and the involvement of people with ID in ACP. It is recommended that relatives and professionals should be informed about the content of ACP and professionals should be trained in communicating in advance about wishes for future care.

\section{Introduction}

People with intellectual disabilities (ID) have 2.5 times as many health problems as people without ID (van Schrojenstein Lantman-De Valk et al. 2000). Respiratory disease and circulatory diseases are the main causes of death of people with ID (O'Leary et al. 2018). The life expectancy of people with ID has increased over the past few decades, with a shift from sudden deaths and brief illnesses to more lengthy illness processes. As a result, an increasing number of people with ID require palliative care (Janicki et al. 1999; Patja et al. 2000; Coppus 2013; Heslop et al. 2013).

The World Health Organization defines palliative care as 'an approach that improves the quality of life of patients and their families facing the problem associated with life-threatening illness, through the prevention and relief of suffering by means of early identification and impeccable assessment and treatment of pain and other problems, physical, psychosocial and spiritual'.

It is known from previous research that health care professionals find it difficult to recognise a need for palliative care in people with ID (Vrijmoeth et al. 2016b). This difficulty often stems from the fact that people with limited cognitive and communicative capabilities are not always able to clearly express their needs and wishes (Stein 2008; Tuffrey-Wijne \& McEnhill 2008; Tuffrey-Wijne et al. 2010a; Tuffrey-Wijne et al. 2010b; Heslop et al. 2013; Stancliffe et al. 2016; Vrijmoeth et al. 2016a). Professionals who care for people with ID do not feel sufficiently trained in providing palliative care, and they often find it difficult to discuss vulnerability and future death (Tuffrey-Wijne et al. 2010b; Bekkema et al. 2014a; Voss et al. 2017).

The process in which professionals, patients and their relatives discuss wishes and options for future care is called advance care planning (ACP). Ongoing processes of ACP address all kinds of concerns across the physical, psychological, social and spiritual domains. Documentation of wishes and decisions is crucial to enable them to be taken into account in future decision-making (Rogne 2013). Identifying wishes for future care at an early stage puts patients in more control of their own care and leads to more effective care (Chan \& Pang 2010; Hammes et al. 2012; Brinkman-Stoppelenburg et al. 2014). ACP also reduces the risk that patients, relatives and professionals are faced with unforeseen situations and lets professionals act with greater self-confidence (Detering et al. 2010; Heslop et al. 2013). ACP can be important at any stage in life but is particularly important in the palliative phase because it helps to ensure that patients receive treatment and care in accordance with their wishes and expectations at the end of life (Heslop et al. 2013; McKenzie et al. 2017).

To date, research about the use and content of ACP in the palliative phase has mainly concentrated on the general population (Brinkman-Stoppelenburg et al. 2014; Houben et al. 2014; Mistiaen et al. 2014; Voss et al. 2017). The aim of this study is to explore how ACP is performed for people with ID and how this is experienced by relatives and professionals. The key questions in this study are as follows: How 
Voss, H., Vogel, A., Wagemans, A.M.A., Francke, A.L., Metsemakers, J.F.M., Courtens, A.M., Veer, A.J.E. de. Advance care planning in the palliative phase of people with intellectual disabilities: analysis of medical files and interviews. Journal of Intellectual Disability Research: 2019, 63(10), p. 1262-1277

does ACP take place in the palliative phase of people with ID and how is this perceived? The associated sub-questions are as follows: (1) What is the reason for starting ACP? (2) What agreements are documented and/or discussed in ACP? (3) Who is involved in ACP? (4) How are the wishes of people with ID taken into account in ACP?

\section{Method}

\section{Procedure}

This study consisted of (1) quantitative analysis of medical files of people with ID in the palliative phase and people with ID who recently died after an identifiable period of illness and (2) supplementary prestructured interviews with care professionals and relatives of the people with ID whose files had been studied.

In the Netherlands, people with ID generally live with their family or independently with support, in a (small-scale) group home in the community or in a large residential setting. Data in this study were collected in six organisations in the Netherlands caring for people with mild to severe ID living in group homes with 24-h care or in residential settings. On a day-to-day basis, they are supported by carestaff, and they receive medical care from a physician employed by the organisation. Some of these physicians are medical ID specialists. Medical ID specialists receive 3 years of specialist training in the care for people with ID.

Physicians reviewed all their current patients and asked the surprise question to identify people with ID who were in the palliative phase during the study period of May 2016 to March 2017. The surprise question is as follows: 'Would you be surprised if this patient died within a year?' If the physician's answer to this question was negative, the person with ID was seen as in the palliative phase and therefore nominated for the study. The surprise question features in many European tools for identifying patients in the palliative phase (Maas et al. 2013). Physicians also nominated all people with ID who had died no more than 6 months prior to the study period after an identifiable period of illness.

This procedure resulted in 117 nominated persons in the palliative phase and 47 recently deceased persons. The following background characteristics were recorded for each person: name of organisation, age, gender, cause of ID, severity of ID, living situation, life-threatening illness or cause of death, and relatives involved. A selection was made based on age, severity of ID, living situation, and life-threatening illness or cause of death. A spread in these variables was required to do justice to the diversity among people with ID, which was also expected to be related to how ACP is performed.

Eventually, 32 people with ID in the palliative phase and 34 deceased people with ID were selected for the study, regardless of the availability of relatives. Of this group, relatives of 15 people with ID in the palliative phase and relatives of 15 deceased approved to check medical files and were interviewed. Physicians $(n=10)$ and care-staff $(n=23)$ of the people with ID were also interviewed. In the case of three people with ID, two professionals were interviewed because the first interview gave insufficient additional information.

\section{Medical files}

The extraction form for the files was developed by the authors of this article in collaboration with experts in palliative care for people with ID, based on practical experience and the existing literature on this subject (see Appendix A). The analysis of the medical files $(n=30)$ provided factual information about the documentation of agreements and communication regarding ACP. To determine the reliability of the data extracted, 19 files were studied by two authors independently $(\mathrm{A}$. W. and $\mathrm{H}$. V. or A. V. and H. V.). After it had been established that the extracted data were in agreement (100\%), the remaining files were studied by one author (A. W., A. V. or H. V.). 
Voss, H., Vogel, A., Wagemans, A.M.A., Francke, A.L., Metsemakers, J.F.M., Courtens, A.M., Veer, A.J.E. de. Advance care planning in the palliative phase of people with intellectual disabilities: analysis of medical files and interviews. Journal of Intellectual Disability Research: 2019, 63(10), p. 1262-1277

\section{Telephone interviews}

The primary aim of these pre-structured interviews was to validate and refine the information about the use of ACP that had not been found in the files. An additional aim was to gain some information about experiences of relatives and professionals with ACP. The interview items were directly related to the items of the extraction form for the medical files.

The interview started with closed, factual questions (e.g. 'Did you discuss care as the person's illness progressed?'), followed by an open question about their experiences (e.g. 'How did you experience these discussions?'). These items were addressed in the interviews of both the relatives and the professionals concerning people with ID in the palliative phase or who had died, although the questions were adapted to fit the interviewee's situation. All interviews were conducted between January and October 2017 and were recorded. Interviews with relatives took an average of $15 \mathrm{~min}$ (range 7-31 $\mathrm{min}$ ); interviews with professionals lasted $10 \mathrm{~min}$ on average (range 4-20 min).

Table 1 provides characteristics of the relatives and professionals who were interviewed. The largest group of relatives (43\%) saw the person with ID at least once a week, $27 \%$ saw the person with ID once to twice a month and $30 \%$ saw him or her several times a year. Professionals had been working with people with ID for 14 years on average (range 2-31 years) and had been caring for the person in question for an average of 5 years (range $0.2-16$ ).

\section{[table 1]}

\section{Analysis}

Descriptive analysis using STATA (version 14) was performed on the data from the medical files and the closed questions from the interviews. Open questions in the interviews were analysed as follows: The recorded interviews were listened to, and an extensive summary was made, also containing the actual quotations about the personal experiences with ACP. The quotations were independently coded by two authors (H. V. and A. V.), using keywords that were taken from the own words of the interviewees. The codes were compared by these two authors and clustered into significant themes. $A$ selection of $10 \%$ of the interviews were replayed and analysed by another co-author (A. F. or A. W.) to validate the summaries and the identified themes.

\section{Ethical approvals}

The research protocol was assessed and approved by the Medical Ethical Committee of the University Medical Centre Amsterdam. Participation in the study was voluntary, and all relatives and professionals gave their informed consent. Research data were anonymised for analysis.

\section{Results}

\section{Background characteristics of the people with intellectual disabilities}

Table 2 provides background characteristics of the people with ID. Cause of the ID was unknown in the majority of cases (60\%), 20\% had Down's syndrome and the cause for the remaining $20 \%$ was another chromosomal abnormality, a metabolic disorder or another reason.

\section{[table 2]}

\section{Start of advance care planning}

The medical files of seven of the 30 people with ID contained no report of (recognition of) palliative care needs or delivery of palliative care, even though they had been selected by their physician as a person in the palliative phase or who had died. The other files of people with ID in the palliative phase $(n=11)$ or who had died $(n=12)$ did contain reports of palliative care. In half of the files of the 12 
Voss, H., Vogel, A., Wagemans, A.M.A., Francke, A.L., Metsemakers, J.F.M., Courtens, A.M., Veer, A.J.E. de. Advance care planning in the palliative phase of people with intellectual disabilities: analysis of medical files and interviews. Journal of Intellectual Disability Research: 2019, 63(10), p. 1262-1277

people with ID who had died, the first report of a need for palliative care was less than 1 month before death; in four cases, it was between 1 month and 6 months before death; and in two cases, it was more than 6 months before death (with a maximum of 4.5 years).

In interviews, professionals and relatives explained that they experienced difficulty in recognising care needs due to the communicational and cognitive disabilities of the person with ID; see Quote 1. In 19 of the 30 cases, professionals said that there was a clear start of palliative care marked by a substantial deterioration in the health of the person with ID or the diagnosis of a life-threatening illness. The need to start ACP was evident from the person's behaviour; see Quote 2. In the remaining cases, professionals said that there was no palliative phase $(n=2)$, were unsure whether there was a palliative phase $(n=2)$ or said that there was no clear lead-up and/or identification of the palliative phase $(n=7)$, for example, because it was a lengthy process of gradual deterioration. Professionals sometimes found it difficult to initiate discussions about wishes and options for future care, because they feared resistance from relatives to engage in such discussions and it was an emotional topic for them.

\section{[Box 1]}

\section{Advance care planning agreements}

Although palliative care needs or delivery of palliative care was not documented in all medical files, ACP agreements were recorded for 29 of the 30 people with ID. These were mainly medical decisions (Table 3). Six of the seven people with ID who had no record of palliative care according to their medical file did have a do-not-attempt-resuscitation order. For two-thirds of the people with ID $(n=20)$, there were multiple reports in the medical files of discussions and/or agreements about future care. In the cases of 11 people with ID, agreements in the file were extended or modified because the person's situation became more fragile or, conversely, stabilised.

\section{[table 3]}

While often not documented in the medical files, it transpired in the interviews that relatives and professionals also discussed issues concerning the (social) environment and daily activities and personal care. Occasionally professionals made use of an aid for discussing wishes and making agreements, such as a checklist with topics that are important in the palliative phase. This was found to be helpful for ACP. However, no clear organisational procedures were mentioned about how or when to have ACP discussions or make agreements.

The interviews showed that, because it was often unclear how the deterioration in the person with ID would progress, relatives frequently found it difficult to talk and take decisions about the future; see Quote 3. Professionals thought it was important to take time and give relatives a chance to get familiar with the idea that their loved one was deteriorating. As it became clearer as the illness progressed what was possible and what not, agreements could be made about future care. This brought peace in the final phase of life; see Quote 4.

\section{[Box 2]}

\section{Involvement in advance care planning}

The medical files indicated that $90 \%$ of people with ID for whom ACP agreements had been made $(n=29)$, there had been discussions between the physician and relatives about these agreements and/or that relatives agreed with decisions. In four cases, it was reported that the person with ID attended ACP discussions. In most files $(n=18)$ was reported that besides the physician, other professionals were involved in ACP, such as daily care-staff,behavioural experts and/or spiritual 
Voss, H., Vogel, A., Wagemans, A.M.A., Francke, A.L., Metsemakers, J.F.M., Courtens, A.M., Veer, A.J.E. de. Advance care planning in the palliative phase of people with intellectual disabilities: analysis of medical files and interviews. Journal of Intellectual Disability Research: 2019, 63(10), p. 1262-1277

caregivers. Medical specialists at the hospital were involved in ACP in four cases. An internal supporting palliative team was involved in one case.

In the interviews, professionals acknowledged the importance of relatives' involvement; see Quote 5. Relatives said that they received sufficient, clear information about how the illness could be expected to progress and the pros and cons of possible decisions. They also perceived they were given sufficient room to express their own wishes for future care. However, some relatives felt it was unclear what role and responsibilities they had in decisions about future care, and not all relatives were informed about their legal role as representative of the person. In most cases, there was agreement between relatives and professionals concerning views on the future care for the person with ID or relatives trusted professionals to make a good decision in the interests of the person with ID; see Quote 6.

\section{[Box 3]}

\section{[Box 4]}

\section{Wishes of people with intellectual disabilities in advance care planning}

In the interviews, professionals in 22 of the 30 cases said that it was not possible to involve the person with ID in ACP because the person did not have the intellectual capacity, could not oversee the situation and/or was too fearful to discuss the matter; see Quote 7. In eight cases, it was possible to involve the person with ID to some extent, according to the professionals, by informing them of the illness and/or deterioration in a simple manner adapted to their cognitive level and capabilities. The persons' own wishes about future care were mentioned in the medical file in only four out of 30 cases. The interviews also revealed that relatives and professionals did believe they had acted on the basis of the persons' wishes wherever possible. In half of the cases, relatives and professionals said that they had discussed with the person in question what they found important in their life. They looked at what the person with ID would want and at ways of taking account of their wishes; see Quote 8. Sometimes, this discussion was conducted with the help of a spiritual caregiver. In the case of people with ID who could not express themselves verbally, their wishes were deduced from their behaviour and agreements made on this basis. In this way, the person with ID remained in control.

\section{[box 5]}

\section{Discussion}

This study shows that ACP mainly takes place in the final phase of the life of people with ID.

Agreements documented in the medical files mainly focus on medical end-of-life decisions made by relatives and professionals. No palliative care needs were reported in the files of $20 \%$ of the deceased persons with ID, while such needs were only reported less than 1 month before death for a further $40 \%$ of the deceased persons with ID. Hence, identification of changing needs and adjusting the provision of care as needs change is not always done proactively but rather seems responsive to problems that arise. Moreover, the findings in our study are in accordance with previous research showing that professionals find the end of life a difficult and emotional topic, which could lead to postponing or avoiding conversations about future care (Brown et al. 2003; Bekkema et al. 2014a; Wiese et al. 2014; McKenzie et al. 2017).

The interviews in this study revealed that wishes and options for future care were discussed with regard to the persons' social environment, activities and personal care, but documentation about discussions and/or agreements concerning psychosocial and spiritual aspects of palliative care were not found in the medical files. Earlier research also showed that there was little documentation about the process of decision-making and the roles of the people involved in the case of end-of-life decisions for people with ID (Wagemans et al. 2010). 
Voss, H., Vogel, A., Wagemans, A.M.A., Francke, A.L., Metsemakers, J.F.M., Courtens, A.M., Veer, A.J.E. de. Advance care planning in the palliative phase of people with intellectual disabilities: analysis of medical files and interviews. Journal of Intellectual Disability Research: 2019, 63(10), p. 1262-1277

In addition, the interviews indicated that relatives were often involved in ACP and that collaboration between professionals, relatives and - where possible - the person with ID often went well. Previous research showed that it is important for professionals to develop a bond with relatives and inform and involve them in the care of the person with ID (Bekkema et al. 2015). Physicians attached considerable importance to relatives' opinions, and they often leave the assessment of a persons' quality of life to the relatives (Wagemans et al. 2012). In the current study, some relatives felt that decisions about future care rested on their shoulders. Although the opinion of relatives can be very valuable and in some cases, the deciding factor, it is important that professionals inform relatives of the legal situation of representatives and the associated responsibilities.

This study showed that people with ID were often not involved directly in ACP. Relatives and professionals explained that they looked carefully at the person in question and from their perspective, thereby acting on behalf of the persons' interests. However, it is known from previous research that people with mild ID want to be informed about their health status, to be asked more about their care wishes and to be listened to (Tuffrey-Wijne et al. 2006; Bekkema et al. 2016; McKenzie et al. 2017). In line with previous research, we also recommend that relatives and professionals consider ways of involving people with ID in ACP rather than assuming, possibly incorrectly, that it would be too burdensome for them to become involved (van Thiel et al. 1997; Tuffrey-Wijne \& Mcenhill 2008; Tuffrey-Wijne et al. 2010b; Wagemans et al. 2010; Bekkema et al. 2014b; McKenzie et al. 2017). Further research that includes the perspective of people with ID themselves would be valuable to obtain more in-depth information about the wishes and needs for ACP.

\section{$2 \quad$ Strengths and limitations}

In this study, medical files of people with ID were examined rather than their daily care files. This means that reports by care-staff were not examined. However, in the participating organisations, the physician is responsible for the medical policy on palliative care, and if any agreements had been made, these should have been documented in the medical files. A second limitation concerns the retrospective character of part of this study. Professionals of deceased people with ID sometimes found it difficult to answer the questions because they could no longer recall the process of ACP. However, if this meant that an interviewee gave very limited information, other professionals were approached for an additional interview. A final limitation concerns a possible selection bias. Relatives who were satisfied with the care provided or who are more closely involved might be more likely to participate than relatives who were less satisfied or less involved in the care. Also, the findings may not apply to individuals who live at home independently or with their family.

A strength of this study is that insights were obtained from multiple sources of information.

Furthermore, the selection based on a spread in the background characteristics of people with ID meant that the diversity of the group was taken into account, giving as comprehensive a picture as possible of the use of ACP for people with ID.

\section{Conclusions}

This study shows that ACP in the palliative phase of people with ID is not often performed to discuss possible issues and wishes for care in the future but rather takes place in response to acute medical issues at the end of life. Despite the fact that relatives and professionals were involved with the person with ID and worked well together, professionals found it difficult to recognise palliative care needs, initiate ACP discussions, document wishes and agreements in advance and find ways to involve the person with ID. It is important that professionals learn to proactively identify and discuss changes in care needs with the person with ID and/or relatives. To achieve this, relatives and professionals should be informed about the essence of palliative care and ACP, and professionals should be trained in communication and documentation of wishes and agreements for future care. Furthermore, it is important to hear from people with ID themselves how they wish to be involved in ACP. In this way, palliative care can be provided in line with what the person wants and needs. 
Voss, H., Vogel, A., Wagemans, A.M.A., Francke, A.L., Metsemakers, J.F.M., Courtens, A.M., Veer, A.J.E. de. Advance care planning in the palliative phase of people with intellectual disabilities: analysis of medical files and interviews. Journal of Intellectual Disability Research: 2019, 63(10), p. 1262-1277

We would like to thank the physicians who generously made time to contribute to this study. $5 \quad$ Source of funding

This research was funded by ZonMw (the Netherlands Organisation for Health Research and Development), project number 844001201 .

\section{Conflict of interest}

The authors declare that there is no conflict of interest.

7 Appendix A: Extraction Form for File Investigations

General

Researcher name:

Date of file investigation:

Client number:

Age:

Sex:

Cause of intellectual disability:

Level of intellectual disability:

Current accommodation situation:

Medical reason for limited life expectancy:

- Dementia

- Malignancy

- CVA

- Heart failure

Client

- COPD

background

- Metabolic disorder

Other relevant

- General physical deterioration

- Other

The relatives involved: yes/no?

Who?

Estimated life expectancy:

- >12 months

- $\leq 12$ months

- Unknown

Deceased:

- Cause of death?

- Place of death?

Clear marking of the palliative phase? (Professional expects client to live one more year at most/surprise question is answered in the Palliative care negative)

Other relevant Yes/No information?

If yes, when did palliative care start?

Have ACP agreements been made?

Yes/No

Other relevant

ACP agreements

What has been agreed?

information?

- Resuscitation policy/DNAR order? 
Voss, H., Vogel, A., Wagemans, A.M.A., Francke, A.L., Metsemakers, J.F.M., Courtens, A.M., Veer, A.J.E. de. Advance care planning in the palliative phase of people with intellectual disabilities: analysis of medical files and interviews. Journal of Intellectual Disability Research: 2019, 63(10), p. 1262-1277

In case of DNAR: date of order?

- Hospitalisation: yes/no?

- Intensive care: yes/no?

- Agreements on diagnostic tests: yes/no?

- Agreements on treatment: yes/no?

- Antibiotics: yes/no?

- Agreements on artificial nutrition or hydration: yes/no?

- Policy geared to comfort/dealing with symptoms: yes/no?

o Pain control

O Reducing anxiety

o Reducing unrest

o Other?

- Place of death discussed? Is this the wish of the client/relatives/supervisors?

Yes/No

o Client's wishes concerning ACP discussed?

Yes/No

If yes, have they been adhered to?

Yes/No

- Relative's wishes concerning ACP discussed?

Yes/No

If yes, have they been adhered to?

Yes/No

- Physician

O ID physician

o General practitioner

o Basic physician

- Client

- Relative

o Parent

o Brother/sister

Who was o Cousin/niece/nephew

Other relevant

o Friend information?

o Other

- Legal representative/Mentor (non-family)

- Daily care-staff

- Other care professional

- Other

o Who?

Were there factors that made communication difficult?

Yes/No 
Voss, H., Vogel, A., Wagemans, A.M.A., Francke, A.L., Metsemakers, J.F.M., Courtens, A.M., Veer, A.J.E. de. Advance care planning in the palliative phase of people with intellectual disabilities: analysis of medical files and interviews. Journal of Intellectual Disability Research: 2019, 63(10), p. 1262-1277

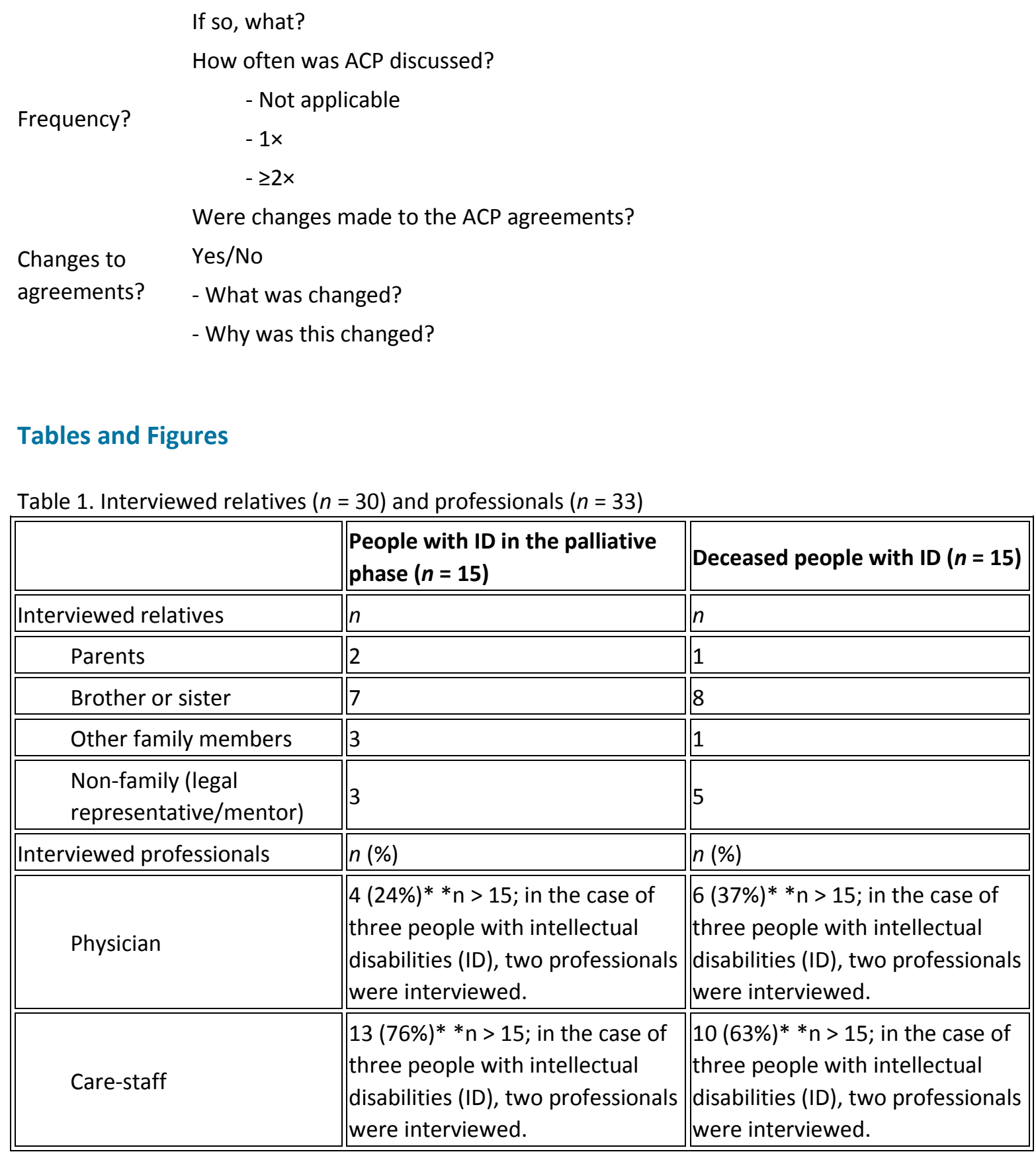

${ }^{*} n>15$; in the case of three people with intellectual disabilities (ID), two professionals were interviewed.

Table 2. Background characteristics of people with intellectual disabilities (ID)

\begin{tabular}{|c|l|l|||}
\hline & $\begin{array}{l}\text { People with ID in the palliative } \\
\text { phase }(n=15)\end{array}$ & $\begin{array}{l}\text { Deceased people with ID } \\
(\boldsymbol{n}=15)\end{array}$ \\
\hline \multirow{3}{*}{ Average age (years) } & 69 & 67 \\
\hline Sex, $n$ & Min. 40 & Min. 25 \\
\hline \hline Male & Max. 96 \\
\hline \hline Female & 6 & \\
\hline
\end{tabular}


Voss, H., Vogel, A., Wagemans, A.M.A., Francke, A.L., Metsemakers, J.F.M., Courtens, A.M., Veer, A.J.E. de. Advance care planning in the palliative phase of people with intellectual disabilities: analysis of medical files and interviews. Journal of Intellectual Disability Research: 2019, 63(10), p. 1262-1277

\begin{tabular}{|c|c|c|}
\hline & $\begin{array}{l}\text { People with ID in the palliative } \\
\text { phase }(n=15)\end{array}$ & $\begin{array}{l}\text { Deceased people with ID } \\
(n=15)\end{array}$ \\
\hline \multicolumn{3}{|l|}{ Degree of ID, $n$} \\
\hline Mild & 4 & 4 \\
\hline Moderate & 6 & 6 \\
\hline Severe & 5 & 5 \\
\hline \multicolumn{3}{|l|}{ Place of care, $n$} \\
\hline Residential setting & 12 & 13 \\
\hline $\begin{array}{l}\text { Community setting }-24-h \\
\text { supervision }\end{array}$ & 3 & 2 \\
\hline \multicolumn{3}{|l|}{ Life-threatening illness, $n$} \\
\hline General physical deterioration & 6 & 5 \\
\hline Dementia & 6 & 4 \\
\hline Malignancy & 2 & 3 \\
\hline Other & 1 & 3 \\
\hline
\end{tabular}

Box 1

Quote 1: Brother of person with ID in the palliative phase (male, moderate ID, general physical deterioration, aged 71) "His pain threshold is very high, he never complains, so it is incredibly difficult to determine if something's wrong. He doesn't communicate anything. That makes it so difficult." Quote 2: Professional who cared for a person with ID (female, mild ID, dementia, aged 86) "She began to refuse her food: 'I don't want any more, I'm tired'; that's when the turning point came. And then there were discussions, and agreements were made."

Table 3. Documentation of advance care planning agreements in medical files

\begin{tabular}{|c|c|c|}
\hline & $\begin{array}{l}\text { People with ID in the palliative phase } \\
(n=15)\end{array}$ & $\begin{array}{l}\text { Deceased people with ID } \\
(n=15)\end{array}$ \\
\hline Agreement about & $n$ & $n$ \\
\hline DNAR & 14 & 14 \\
\hline Diagnostic tests & 3 & 1 \\
\hline Medical treatments & 5 & 8 \\
\hline Hospitalisation admissions & 7 & 7 \\
\hline Intensive care treatment & 6 & 4 \\
\hline Antibiotics & 1 & 4 \\
\hline $\begin{array}{l}\text { Artificial nutrition or } \\
\text { hydration }\end{array}$ & 3 & 2 \\
\hline $\begin{array}{l}\text { Place of care at the end of } \\
\text { life }\end{array}$ & 1 & 1 \\
\hline
\end{tabular}

- DNAR, do-not-attempt resuscitation; ID, intellectual disabilities. 
Voss, H., Vogel, A., Wagemans, A.M.A., Francke, A.L., Metsemakers, J.F.M., Courtens, A.M., Veer, A.J.E. de. Advance care planning in the palliative phase of people with intellectual disabilities: analysis of medical files and interviews. Journal of Intellectual Disability Research: 2019, 63(10), p. 1262-1277

Box 2

Quote 3: Father of a person with ID in the palliative phase (male, moderate ID, progressive illness, aged 40) "No, we don't have discussions about that [ACP]. It would be different if we expected him to have to go to hospital next week. Then, of course, we'd be preparing for something that is definitely going to happen. But we don't discuss anything that is possibly going to happen in the future." Quote 4: Brother of a deceased person with ID (male, moderate ID, neurological condition, aged 66) "The nice thing for us as a family was really that as soon as he got the announcement that he was not going to be operated on, a kind of peace came over him. He never became angry again then or escalated things or whatever. He passed away very peacefully, actually."

Box 3

Quote 5: Professional caring for a person with ID in the palliative phase (female, mild ID, general physical deterioration, aged 85) "I try to involve them [family] as much as possible so they know how she's doing. And about the deterioration, how it's progressing and what they [family] think about that."

Box 4

Quote 6: Aunt of a deceased person with ID (female, moderate ID, malignancy, aged 83) "I have to say that I'm very satisfied with how it went. We only disagreed when they [professionals] still wanted to arrange the examination - or at any rate wanted to consult a physician - and I didn't like the sound of it, but we talked about all of this very openly and clearly. I didn't feel I was being pressured either. And eventually I thought: they spend so much time with her, they'll be better able than me to estimate whether she can cope with this."

Box 5

Quote 7: Physician caring for a person with ID in the palliative phase (female, mild ID, general physical deterioration, aged 82) "Getting older .... I don't know what I should say to her about that. That she is getting older and she will eventually die? I think that would only make her anxious."

Quote 8: Mentor of a deceased person with ID (female, mild ID, malignancy, aged 53) ".... And that was what I already said at her level, right. When I was talking to her about it or when the daily care-staff was, because of course they were much closer to her in fact than I was because I only come every now and then of course. But we've built that up, and when talking to people she really trusted she would say, listen, if I can't smoke any more cigarettes and can't drink any more coffee then I'm done. Then I don't really see the point any more. You can say that's oversimplifying things but if you put it in the context of that lady's life and what was important for her .... That was her life. And then I think you have to take that into account." 